\title{
Estimating railway infrastructure project cost from transferring nominal price to real price by considering the working time possessions
}

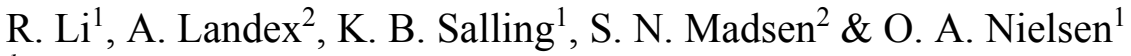 \\ ${ }^{I}$ DTU Transport, Technical University of Denmark, Denmark \\ ${ }^{2}$ Rambøll, Denmark
}

\begin{abstract}
The purpose of the paper is to estimate a railway project construction cost based on the nominal market price. Currently, estimation of project costs within railway infrastructure procurement is particularly challenging due to: 1) construction costs highly depend on possession timeframes and duration and 2) railway construction work costs are not transparent in the market.

This paper suggests separating the costs into 3 sub-categories: materials, labour and machinery. Evidently, the materials are further broken down into subcomponents, which then remains fixed, whereas the cost of labour and machinery are varying depending on the working time possessions presented through the closure of the railway line. The effective working hours, type of construction work and construction speed are used as constraints to ensure the track closure plan remains feasible.

To demonstrate the approach, a Danish railway construction project, the new line to the fixed link across Fehmarn Belt, is introduced, where it is shown that the non-material cost is about $19 \%$ of the total expenditure. By assuming three sets of track blocking scenarios with the same amount of construction work it is proven that, given an optimal track closure plan, the overall cost can be reduced by $2.7 \%$. It can be concluded that our approach using an optimal working possession plan can identify the low-cost track closures.

Keywords: cost estimation, Greenfield-market price, working possession, track closure, phase-based planning, railway infrastructure project, construction project planning.
\end{abstract}




\section{Introduction}

Compared to road and other construction work, the estimation of railway infrastructure project costs is particularly challenging, because construction costs depend highly on the possession timeframes and duration (Rambøll [1]). Today it is not often totally shutting down the existing railway service just on any infrastructure maintenance and renewal purpose (Forsgren et al. [2]). 17\% passengers (2009 figure in Ponti et al. [3]) and 10.2\% freights (2010 figure in European Commission [4]) are using railway as a transport mode in Europe. Society requires that the interruption of existing railway operations is as little as possible by any railway infrastructure project. Most of the railway infrastructure work therefore has to be done in the night possessions, weekends or in the particular weekday daytime possessions when the track is not needed by trains (literature overview in Budai-Balke [5]). Railway Infrastructure Managers (IMs) have been suffering much higher maintenance costs in those special possessions. Firstly the working intensity at night is naturally low (Darolia [6]). When labour works at normal sleeping hours at night, the attention decreases rather fast. Loss of time increases. In the Fehmarn Belt project, the general time loss at night is estimated around $10 \%$ to $15 \%$ of possession duration depending on the construction work (Rambøll [7]); secondly the construction works between running traffic requires special attention with regard to safety settlements before and after construction work. The shorter the possession duration, the higher percentage of un-construction safety settlement time need to be paid. This ultimately leads to an even more expensive project plan; lastly the labour wages is higher in weekend and at night. It shows $150 \%$ and $200 \%$ of labour costs working in weekend daytime and at night respectively in Denmark (labour law in Denmark). Due to those reasons, the construction cost for railways is typically higher than the road and other construction project in which the most of work are executed in the normal working hours.

Railway construction work prices are not transparently given in the market. As mentioned, the prices corresponding to the working time can only be estimated from case to case; while in the road construction market, nominal prices are rather relatively standardized known as Greenfield-market prices (G-Price), barmarkspriser in Danish (Rambøll [1]). G-price, which can be found in many construction websites, is the base price corresponding to the standard 37 working hours per week during weekday daytime in Denmark. If planners collect such nominal prices instead of real prices to estimate the project cost, the risk of budget overrun is high (Flyvbjerg [7], Cantarellia et al. [9]). The calculation in Fehmarn Belt project shows that dam extension real price is $26-153 \%$ more expensive than nominal

G-price if considering the track closure time frames.

The purpose of this paper is to transfer nominal price to real price by considering the working possessions. The method presented in this paper is to help IMs to identify the low-cost solution among alternative track closure plans.

The paper is organized as follows. Section 2 introduces a phase-based calculation method. Five calculation phases and four mathematic formulas are 
developed to guide the overall cost calculation; Section 3 presents the Fehmarn Belt Danish railway construction project from Rail Net Denmark (Banedanmark). The case is used to demonstrate how to use the method to estimate the project costs. Three track closure scenarios are introduced and compared. The main findings and future research direction are discussed; Section 4 summarizes the method and the main achieved results.

\section{Method}

The method introduced by this paper was developed since 2011 when Banedanmark planning track closure for the railway project, Fehmarn Belt. The project shareholders would like to compare the direct costs, and identify the lowcost feasible solution among all proposals. The method is built to estimate the project cost at high level. The cost calculation is based on the available nominal prices from road and other construction market and the detailed project plans.

\subsection{Method phase-based framework}

The main calculations are built in the 5 successive phases:

1. Defining main working possession time frames;

2. Separating the G-price into 3 sub-categories: materials, labour and machinery;

3. Calculating time efficiencies for labour and machinery in each possession;

4. Calculating price indexes per type of construction work per working possession;

5. Calculating and comparing the total cost among proposed track closures corresponding to the feasible working schedules.

\subsection{The descriptions of the calculation phases}

\subsubsection{Phase 1: defining main working possession time windows}

Experience shows that night shift and weekend shift are more expensive, e.g. labour cost around $200 \%$ and $150 \%$ of normal wage respectively in Denmark. Thus, it is important to separate the working possession time windows into subcategories where the labour is pricing differently.

In this phase, the duration of each main working possession is separated into the number of hours per week in 4 subcategories: weekday daytime hours (labour is $100 \%$ paid), weekday night hours (labour is $200 \%$ paid), weekend daytime hours (labour is $150 \%$ paid), and weekend night hours (labour is $200 \%$ paid). The overlap hours between any possible working possessions' combinations need to be marked. The purpose is to plan the construction work realistic at Phase 5 when planning the construction in the combination of possessions. E.g. there exists 7 hours overlap between the weekday night possession (22:00-06:00 Sunday-Thursday) and weekend possession (Friday 22:00-Monday 06:00) if the physical track works are executed in both possessions in the same week. IMs have 
to remember that there are only 4 nights and a weekend possession can be assigned in the project plan.

\subsubsection{Calculation Phase 2: separating the G-price into 3 sub-categories: materials, labour and machinery}

In any railway infrastructure project, the project costs can be divided into non-track closure related e.g. materials, administration; and working time related constructions i.e. dam extension, physical track works etc. Our method suggests separate G-price into 3 subcategories: materials, labour and machinery. The materials cost keeps fixed while the prices of labour and machinery are changing according to the working time possessions presented through the closure of the railway line and detailed project schedule. Eqn (1) shows the G-price structure.

$$
R_{\text {Materials }}^{i}+R_{L}^{i}+R_{M a c}^{i}=1
$$

where:

\begin{tabular}{|c|c|}
\hline $\begin{array}{ll}\text { - } & R_{\text {Materials }} \\
\text { - } & R_{L} \\
\text { - } & R_{\text {Mac }} \\
& i\end{array}$ & $\begin{array}{l}\text { : Material cost ratio in percentage } \\
\text { : Labour cost ratio in percentage } \\
\text { : Machinery cost ratio in percentage } \\
\text { : The index indicates different type of construct }\end{array}$ \\
\hline
\end{tabular}

At this step, the G-prices are collected from the similar construction markets. Many assumptions about material cost ratio, number of labour and machinery, are made by experts. The expected output from this phase is the G-price structure presented by the ratios of 3 subcategories per construction work (Table 2).

\subsubsection{Calculation Phase 3: calculating time efficiencies for labour and machinery}

To keep as much rail traffic operation as possible, night shifts and interval track possessions between running trains are often used. In these possessions, loss of working time due to the safety settlement before and after construction operation occurs. The following eqn (2) calculates the efficiency of labour and machinery through the paying hours divided by the effective working hours.

$$
E_{L}^{i, q}=\frac{\left(T_{\text {Sum }}^{i, q}-T_{\text {Safety }}^{i, q}-T_{O p}^{i, q}\right) \cdot\left(1-p_{\text {loss }}^{q}\right)}{\sum_{j=1}^{n}\left(T_{j} \cdot p p_{j}\right)}
$$

where:

- $E_{L} \quad$ : Working efficiency of labour

- $T_{\text {Sum }} \quad$ : Total number of hours

- $T_{\text {Safety }} \quad$ : Loss of hours due to safety settlements

- $T_{O p} \quad$ : Loss of hours due to running trains

- $q \quad$ : Possession index indicates night shift, weekend possession etc.

- $T_{j} \quad$ : Hours in time subcategories, e.g. 6 hours in weekday night

- $\quad p p_{j} \quad$ : Labour wage factor per time subcategories 
- $\quad p_{\text {loss }}^{q} \quad:$ General loss of time per possession type $q$, e.g. the general loss of time at night is $15 \%$ for physical track works $(q=2)$, so $p_{\text {loss }}^{2}=15 \%$

Phase 3 is prepared to calculate the real unit price per construction work by time possession at next phase. The calculation of machinery efficiency is similar to labour efficiency. The only difference is that the price for the machine renting hours as the denominator is not depending on the time frame $\left(p p_{\mathrm{j}, \mathrm{mac}}=1\right)$. The expected output from this phase is the time efficiency table for labour and machinery per each possession (Table 3 ).

\subsubsection{Calculation Phase 4: calculating price indexes}

Based on the results from Phase 2 and Phase 3, the price indexes per type of construction work per working possession can be calculated by eqn (3).

$$
P^{i, q}=R_{\text {Materials }}^{i}+\frac{R_{L}^{i}}{E_{L}^{i, q}}+\frac{R_{M a c}^{i}}{E_{\text {Mac }}^{i, q}}
$$

where:

- $\quad P^{i, q}$ : Actual price per construction type $i$ per time possession $q$

A real price index comparing to the nominal price can be calculated in this phase. Meanwhile the unfeasible construction and possession combination can be identified in the phase. E.g. installing a switch and crossing is not feasible in a short possession. The real prices among the set of time possessions for each construction work can be benchmarked. The expected output from Phase 4 is the actual construction price table.

\subsubsection{Calculation Phase 5: cost comparison among feasible working plans}

The alternative feasible implementation plans drafted by experience experts according to the amount of the construction work, the sequence of the construction processes, possible track closure periods, resources and the average construction speed etc., before this phase. The feasibility of project plan can be double checked in this phase. The project cost can be calculated in eqn (4) for each track closure proposal. In practice, the cost comparison among alternative scenarios can help IMs to identify the low-cost solution.

$$
T C^{m}=F C+\sum_{i} \sum_{q}\left(C_{i}^{q} \cdot Q_{i}^{q}\right)
$$

where

- $\quad T C^{m} \quad$ : Total cost of scenario $m$

- $F C \quad$ : Fixed cost which is not time depended

- $C_{i}^{q} \quad$ : Unit price per construction type $i$ per possession $q$

- $Q_{i}^{q} \quad$ : Amount of work per construction type $i$ per possession type $q$ 


\section{Case study}

\subsection{Case introduction}

Germany and Denmark have signed an agreement to establish a permanent connection between Rødby and Puttgarden across the Fehmarn Belt. The Fehmarn Belt project, decided on 15 April 2009 (Banedanmark [10]), includes both the fixed link between Rødby and Puttgarden, and the corresponding Danish onshore facilities upgrading (road and railway). This case is focusing on planning a construction work for the onshore railway line between Ringsted and Fehmarn Belt and estimating the construction costs for 3 different track closure plans.

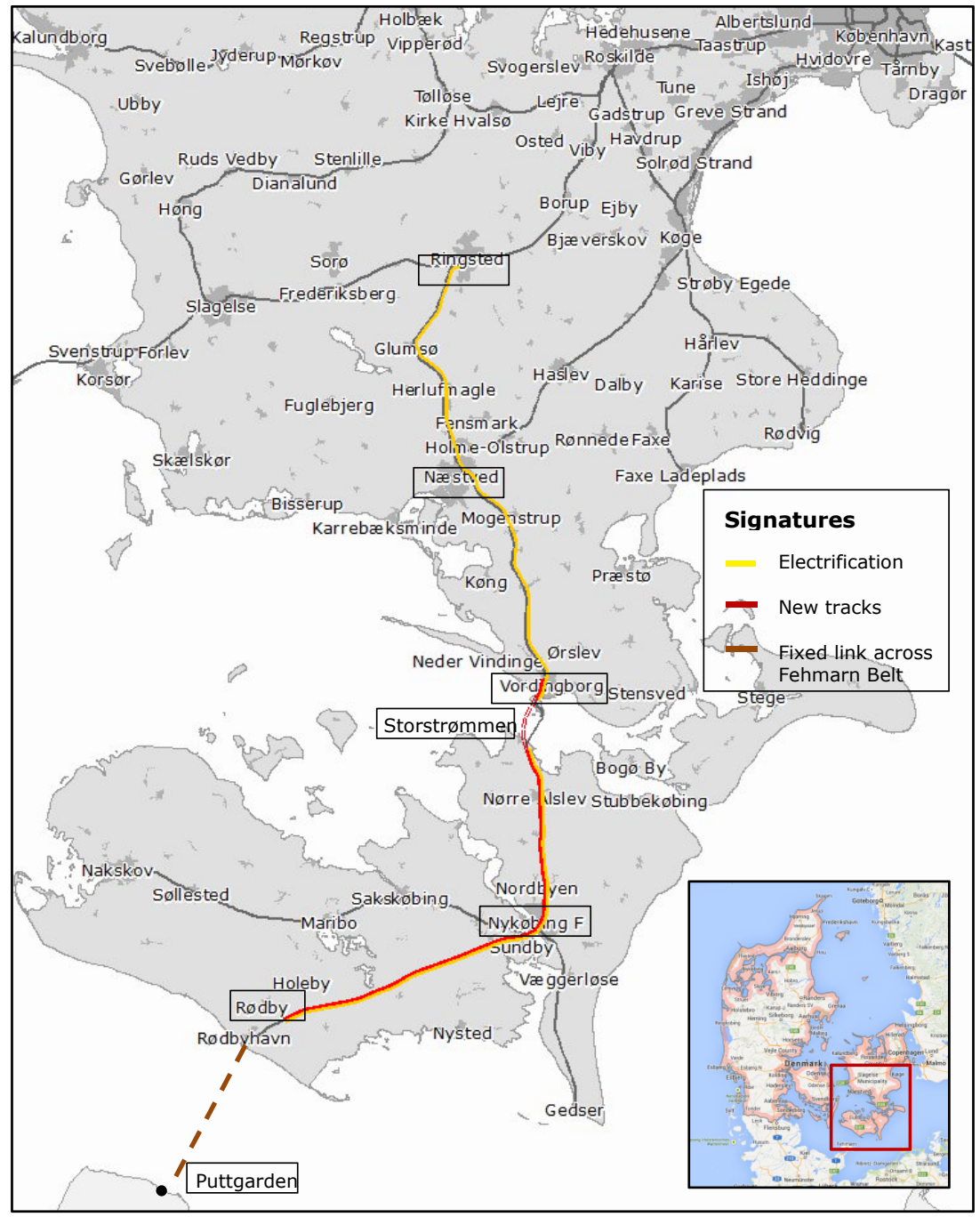

Figure 1: Fehmarn Belt project overview. 
The project mainly includes the following tasks: electrifying the line from Ringsted to Rødby; constructing $55 \mathrm{~km}$ of new track so that the entire line will be double-tracked; upgrading the existing tracks to the speed of $200 \mathrm{~km} / \mathrm{h}$; build and rebuild bridges, including a $3.2 \mathrm{~km}$ new bridge crossing Storstrømmen (Banedanmark [11]).

The project was divided into two main sections, north section and south section. The north section is a double track line from Ringsted to Vordingborg. Today there are 2 trains per hour per direction at rush hours on this section and expected to have 3 passenger trains during the project time (2014-2020) (Madsen [12]). Due to many international and local passengers, it is preferred to remain the existing traffic in the north section in the construction period.

A single track is from Vordingborg to Rødby on south section. There are relatively less local passenger demands between Vordingborg and Nykøbing $F$. and between Rødby and Nykøbing $F$. The section is open to all tracks possession patterns. The cost comparison among the different blocking alternatives is calculated mainly for the south section.

\subsection{Main working possessions}

Four main working possessions in Ringsted-Fehmarn project are defined in Table 1. A "working weekday" is defined in the interval possession. Labour and machinery are working 35 hours per week, equaling 7 hours (paying 7.5 standard hours with 0.5 hours preparation time) per weekday. A "working night" is defined in the night possession where labour cost $200 \%$ (night wage factor) of 37.5 standard hours per week while machinery cost the same as a "working weekday". A "working weekend" is a bit more complex because the possession duration contains 24 night hours and 32 hours in weekend daytime. After considering the labour wage factors, labour cost 96 standard hours while machinery cost 56 standard hours. A "full day" is defined in all day closure possession. A full day work means 24 working hours where the track is totally closed only for infrastructure work. Full track closure is normally planned in summer time (June-August) of the year.

Table 1: Main working possession definitions (Phase 1).

\begin{tabular}{|c|c|c|c|c|c|c|c|c|c|}
\hline \multirow[t]{2}{*}{ Q } & \multirow[t]{2}{*}{ Possesion type } & \multirow[t]{2}{*}{ Period } & \multirow{2}{*}{ 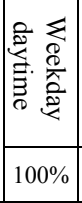 } & \multirow{2}{*}{ 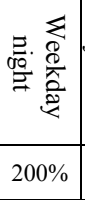 } & \multirow{2}{*}{ 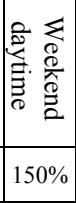 } & \multirow{2}{*}{ 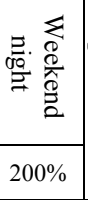 } & \multirow{2}{*}{ 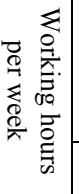 } & \multicolumn{2}{|c|}{$\begin{array}{l}\text { Paying standard } \\
\text { hours } \\
\text { per week }\end{array}$} \\
\hline & & & & & & & & Machine & Labour \\
\hline & $\begin{array}{l}\text { Interval possession } \\
\text { (with running traffic) }\end{array}$ & $\begin{array}{l}\text { 08:00-15:00 } \\
\text { Mon.-Fri. }\end{array}$ & 35 & & & & 35 & 37.5 & 37.5 \\
\hline 2 & Night possession & $\begin{array}{l}\text { 22:00-05:00 } \\
\text { Sun.-Thu. }\end{array}$ & & 33 & & 2 & 35 & 37.5 & 75 \\
\hline 3 & Weekend possession & $\begin{array}{l}\text { Fri. 22:00- } \\
\text { Mon. 06:00 }\end{array}$ & & 8 & 32 & 16 & 56 & 56 & 96 \\
\hline & $\begin{array}{l}\text { All day closure } \\
\text { possession }\end{array}$ & All days & 80 & 40 & 32 & 16 & 168 & 168 & 240 \\
\hline
\end{tabular}




\subsection{Nominal price structure}

The main assumption of nominal price structures in materials, labour and machine per construction work are shown in Table 2 (columns 1-6).

Table 2: G-price structure in Ringsted-Fehmarn project (Phase 2 and 4).

\begin{tabular}{|c|c|c|c|c|c|c|c|c|c|}
\hline $\mathrm{i}$ & Construction work types & 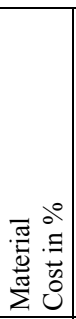 & 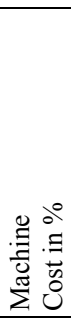 & 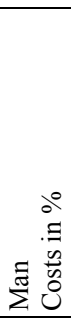 & 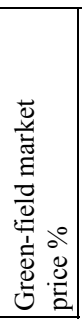 & 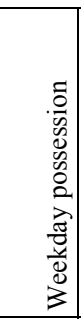 & 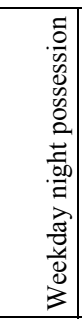 & 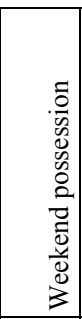 & 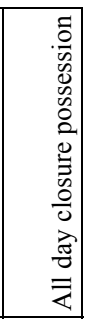 \\
\hline 1 & Earthwork & $10 \%$ & $49 \%$ & $41 \%$ & $100 \%$ & $196 \%$ & $209 \%$ & $140 \%$ & $124 \%$ \\
\hline 2 & Dam extensions & $5 \%$ & $51 \%$ & $44 \%$ & $100 \%$ & $253 \%$ & $215 \%$ & $142 \%$ & $126 \%$ \\
\hline 3 & New bridge & $65 \%$ & $10 \%$ & $25 \%$ & $100 \%$ & $\infty$ & $156 \%$ & $123 \%$ & $114 \%$ \\
\hline 4 & Raising the bridge deck & $35 \%$ & $15 \%$ & $50 \%$ & $100 \%$ & $\infty$ & $167 \%$ & $129 \%$ & $125 \%$ \\
\hline 5 & Track works & $66 \%$ & $21 \%$ & $13 \%$ & $100 \%$ & $106 \%$ & $119 \%$ & $113 \%$ & $108 \%$ \\
\hline 6 & Catenary foundations & $71 \%$ & $20 \%$ & $9 \%$ & $100 \%$ & $\infty$ & $129 \%$ & $110 \%$ & $106 \%$ \\
\hline 7 & Catenary mast & $72 \%$ & $22 \%$ & $6 \%$ & $100 \%$ & $\infty$ & $124 \%$ & $107 \%$ & $104 \%$ \\
\hline 8 & Catenary suspension & $60 \%$ & $28 \%$ & $12 \%$ & $100 \%$ & $\infty$ & $139 \%$ & $113 \%$ & $108 \%$ \\
\hline 9 & Connecting to new track & $0 \%$ & $65 \%$ & $35 \%$ & $100 \%$ & $\infty$ & $\infty$ & $133 \%$ & $118 \%$ \\
\hline 10 & Pipes for fauna passenger & $40 \%$ & $38 \%$ & $22 \%$ & $100 \%$ & $\infty$ & $\infty$ & $123 \%$ & $114 \%$ \\
\hline 11 & Turnout (S and C) & $68 \%$ & $22 \%$ & $10 \%$ & $100 \%$ & $\infty$ & $\infty$ & $110 \%$ & $106 \%$ \\
\hline 12 & Replacement of exi & $93 \%$ & $5 \%$ & $2 \%$ & $100 \%$ & $\infty$ & $107 \%$ & $102 \%$ & $101^{\circ}$ \\
\hline 13 & $\begin{array}{l}\text { New sub-ballast in the existin } \\
\text { track }\end{array}$ & $46 \%$ & $35 \%$ & $19 \%$ & $100 \%$ & $\infty$ & $\infty$ & $120 \%$ & $112 \%$ \\
\hline 14 & Platform works & $66 \%$ & $12 \%$ & $22 \%$ & $100 \%$ & $\infty$ & $\infty$ & $120 \%$ & $112 \%$ \\
\hline 15 & Retaining walls & $45 \%$ & $36 \%$ & $19 \%$ & $100 \%$ & $159 \%$ & $157 \%$ & $119 \%$ & $112 \%$ \\
\hline 16 & Security work & $20 \%$ & $0 \%$ & $80 \%$ & $100 \%$ & $\infty$ & $246 \%$ & $166 \%$ & $139 \%$ \\
\hline
\end{tabular}

Using construction work "earthwork" as a calculation demonstration, the

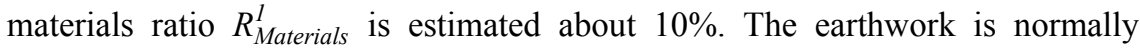
handled by 1 excavator (650 DKK/hour/machine) and 2 workers (275 DKK/hour/labour). So the labour cost ratio can be calculated: $R_{L}^{I}=\left(1-R_{\text {Materails }}\right)\left(\frac{2 \cdot 275}{2 \cdot 275+1 \cdot 650}\right)=49 \%$ and machinery cost ratio is $R_{\text {Mac }}^{I}=1-R_{L^{-}}^{I}$ $R_{\text {Mac }}^{l}=41 \%$.

\subsection{The working efficiencies of labour and machinery}

By using the eqn (2) in method Phase 3, the main working efficiencies of labour and machinery for Ringsted-Fehmarn are calculated and shown in Table 3. Comparing the nominal price, the labour and machinery efficiencies are quite low, because part of budget is actually paying the loss of time, high labour night wage etc. 
Table 3: The working efficiency table (Phase 3).

\begin{tabular}{|c|c|c|c|c|c|c|c|c|c|}
\hline Efficiency item & 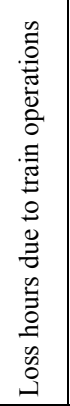 & 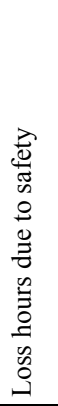 & 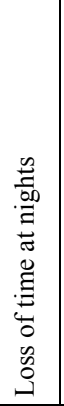 & 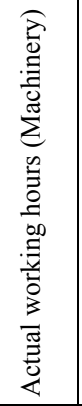 & 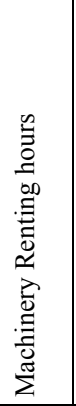 & 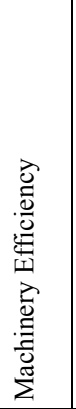 & 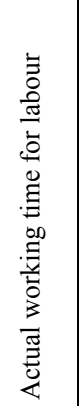 & 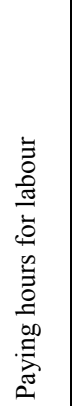 & 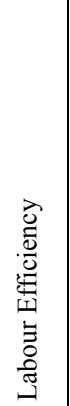 \\
\hline $\begin{array}{l}\text { Weekday working in intervals } \\
(10 \% \text { safety time })\end{array}$ & 14.6 & 3.5 & & 16.9 & 35 & $48 \%$ & 6.9 & 35 & $48 \%$ \\
\hline $\begin{array}{l}\text { Weekday working in intervals } \\
\text { ( } 20 \% \text { safety time) }\end{array}$ & 14.6 & 7.0 & & 13.4 & 35 & $38 \%$ & 13.4 & 35 & $38 \%$ \\
\hline \begin{tabular}{|l} 
Night working \\
(15\% loss at night)
\end{tabular} & & 5.0 & 5.3 & 24.8 & 37.5 & $66 \%$ & 24.8 & 75 & $33 \%$ \\
\hline $\begin{array}{l}\text { Night working } \\
(10 \% \text { loss at night }) \\
\end{array}$ & & 5.0 & 3.5 & 26.5 & 37.5 & $71 \%$ & 26.5 & 75 & $35 \%$ \\
\hline $\begin{array}{l}\text { Weekend working } \\
(15 \% \text { loss at night }) \\
\end{array}$ & & 1.1 & 3.5 & 51.4 & 56 & $92 \%$ & 51.4 & 96 & $54 \%$ \\
\hline $\begin{array}{l}\begin{array}{l}\text { Weekend working } \\
\text { (only in daytime) }\end{array} \\
\end{array}$ & & 1.1 & & 18.9 & 20 & $94 \%$ & 18.9 & 30 & $55 \%$ \\
\hline \begin{tabular}{|l|} 
Totally closure \\
$(15 \%$ loss at night $)$
\end{tabular} & & 1.7 & 8.0 & 158.3 & 168 & $94 \%$ & 158.3 & 240 & $66 \%$ \\
\hline \begin{tabular}{|l} 
Totally closure \\
(only daytime working)
\end{tabular} & & 5.2 & & 142.8 & 168 & $85 \%$ & 142.8 & 168 & $85 \%$ \\
\hline
\end{tabular}

\subsection{Project price indexes}

The project price indexes are calculated in the method Phase 4. "Earthwork" is used to illustrate the calculation. It can be seen that the materials ratio $R_{\text {Materials }}^{l}$ is $10 \%$ which keeps fixed for all possessions. Labour ratio $R_{L}^{1}$ is $49 \%$ in G-price (Table 2). The labour efficiency $E_{L}^{1,1}$ of "Day working in intervals with $10 \%$ Safety time" is $48 \%$ (Table 3 ), while the machinery ratio $R_{M a c}^{1}$ and machinery efficiency $E_{\text {Mac }}^{1,1}$ are $41 \%$ and $48 \%$ respectively. The price index of "earthwork" for weekday possession can be calculated in eqn (3): $P^{1,1}=R_{\text {Materials }}^{l}+\frac{R_{L}^{I}}{E_{L}^{l, 1}}+$ $\frac{R_{M a c}^{I}}{E_{M a c}^{I, I}}=10 \%+101 \%+85 \%=196 \%$. Using the same approach, the price indexes of "earthwork" are 209\%, 140\% and 124\% for night possession, weekend possession and all day closure possession respectively. The actual construction prices per possession are shown in Table 2. The possessions at night and in the weekend are 
more expensive due to high labour cost and naturally time loss. Doing the construction between running trains is the most expensive possession. The longer the all-day closure duration, the cheaper the total cost, because it contains more weekday daytime where labour and machine have the highest working intensity with relatively low costs.

\subsection{Project alternative scenarios}

The project construction period of Fehmarn Belt has been planned from 2014 to 2020. It has been decided that the north section should keep the existing traffic and the construction should only be handled in the day time intervals blocking patterns and weekends. The south section is open to all possessions. There are mainly 3 tracks blocking scenarios in the agreement with Rail Net Denmark (Niras [13]):

- Scenario 1: Total closure of railway line for 4 months in the summer of 2016.

- Scenario 2: Three summer closures in 3 years. The south section is closed for 3, 4 and 3 months in 2015, 2016 and 2017, respectively.

- Scenario 3: Four summer closures in 4 years. The south section is closed for 3, 3, 4 and 3 months from 2014 to 2017 , respectively.

Three detailed construction plans were made according to the above track closure scenarios by the experienced experts. Each plan contains the construction work loads in the combination of the 4 working possessions (Table 4 ).

\subsection{Cost comparison results}

The total cost of each scenario can be calculated according to the detailed construction plan in method Phase 5. Table 4 illustrates "earthwork" cost calculation for the south section in Scenario 1. The similar calculation is handled for all 15 construction works.

Adding the project fixed costs which are not corresponding to the possession settings, the total project cost comparison of base and 3 scenarios can be summarized in Figure 2. Base scenario is calculated based on the nominal G-price. It can be seen that there does exist big risk of cost under-estimation without considering the possession time if we comparing the scenario costs with the base. In Fehmarn Belt project, the overall direct cost difference is around 172 million DKK, $2.7 \%$ of the total project spending. It can be achieved by re-scheduling the track closure and working possessions.

However closure of the railway line for construction purposes can cause more costs for passengers. To identify the overall cost efficiency solution, the passenger loss due to the track closure need to be included. Train operating companies could in the further work provide the related analysis in both short and long term (Li et al. [14]). 
Table 4: Earthwork cost for the south section in Scenario 1 (Phase 5).

\begin{tabular}{|c|c|c|c|c|}
\hline \multirow{2}{*}{$\begin{array}{l}0 \\
\tilde{\Xi} \\
m\end{array}$} & Job Type & Meters & G-Price $(\mathrm{DKK} / \mathrm{m})$ & Total cost \\
\hline & Earthwork & 50,800 & 5,266 & $267,512,800$ \\
\hline \multirow{6}{*}{ 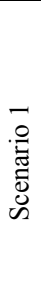 } & Earthwork & Meters & Real Price & Total cost \\
\hline & Weekday working in intervals & 16,900 & 10,341 & $174,769,414$ \\
\hline & Night working & 27,400 & 10,999 & $301,365,999$ \\
\hline & Weekend working & 5,500 & 7,381 & $40,596,799$ \\
\hline & Totally Closure & 1,000 & 6,544 & $6,543,529$ \\
\hline & Summary & 50,800 & & $523,275,741$ \\
\hline
\end{tabular}

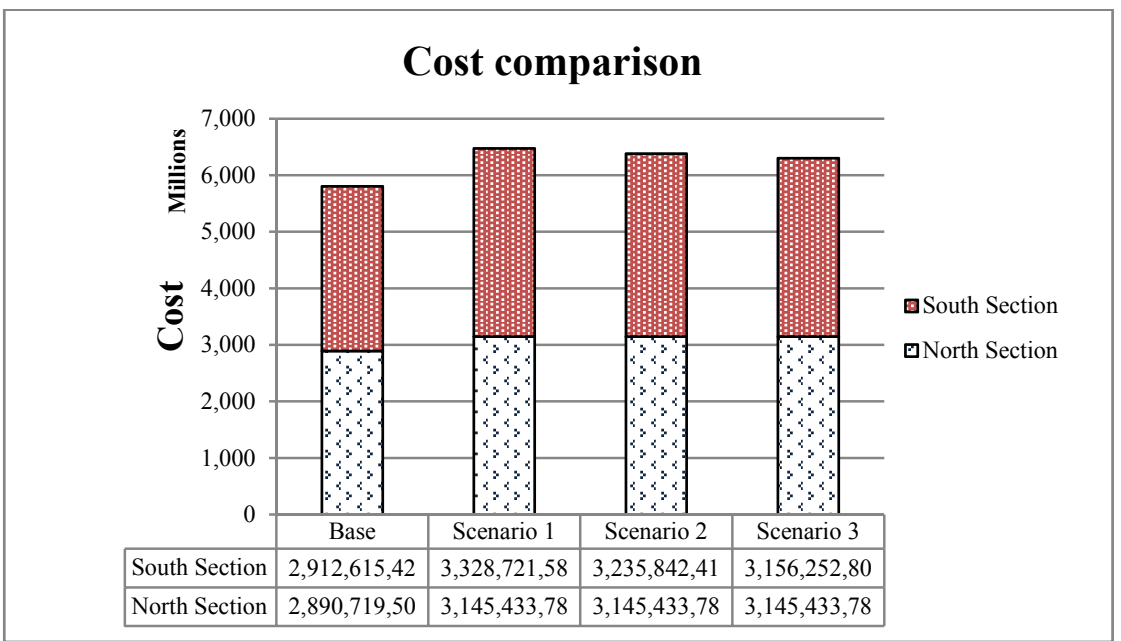

Figure 2: Cost comparison example.

\section{Conclusions}

Estimating project costs within railway infrastructure procurement is challenging due to the facts that: 1) the construction costs are highly depend on possession timeframes; 2) railway real prices are not transparently given in the market. It is practical to use the nominal prices from the similar construction market to do the rough cost estimation. However, it is risky to under-estimate costs without considering the actual railway track closures.

This paper has demonstrated how to estimate the railway construction cost from transferring the nominal price to real price by considering the track closure and the working possession plan. The presented method separates price into 3 sub-categories: materials, labour and machinery. The real prices are calculated by 
remaining the materials fixed whereas the cost of labour and machinery are changing depending on the working time possessions presented through the closure of the railway line.

A Danish railway construction project Ringsted-Fehmarn is introduced in the paper. By comparing three track blocking scenarios with the same amount of construction works. It is proven that the different of direct cost can be top to $2.7 \%$. Thus, it can be concluded that the Greenfield-market price method with the detailed construction possession plan is able to identify the low-cost track closures.

\section{References}

[1] Rambøll, Phase based planning efficient tool, Danish railway conference, pp. 9-10, 2012 (Danish).

[2] Forsgren, M., Aronsson, M. \& Gestrelius S., Maintaining tracks and traffic flow at the same time, Journal of Rail Transport Planning \& Management, volume 3, pp. 111-123, 2013.

[3] Ponti M., Boitani A. \& Ramella F., The European transport policy: Its main issues, Case Studies on Transport Policy, volume 1, pp. 53-62, 2013.

[4] European Commission, EU Transport in Figures 2012, Statistical pocketbook 2012, pp. 19, 2012.

[5] Budai-Balke, G., Operations Research Models for Scheduling Railway Infrastructure Maintenance, Erasmus University, Rotterdam, The Netherlands, 2009.

[6] Darolia R., Working (and studying) day and night: Heterogeneous effects of working on the academic performance of full-time and part-time students, Economics of Education Review, volume 38, pp. 38, 2014.

[7] Rambøll, Notat prisscetning af tilloeg for sporspceringsscenarier, pp. 1-8, 2011 (Danish).

[8] Flyvbjerg, B. Policy and planning for large-infrastructure projects: problems, causes, cures, Environment and Planning B: Planning and Design, volume 4, pp. 578-729, (2007).

[9] Cantarellia, C.C., van Weea, B., Molina, E.J.E. \& B. Flyvbjergb, Different cost performance: different determinants? The case of cost overruns in Dutch transport infrastructure projects, Transport Policy, volume 22, pp. 88-95, 2012.

[10] Banedanmark, Ringsted-Fehmarn project home page: http://uk.bane.dk/visBanearbejde_eng.asp?artikelID=18563, March 2014.

[11] Banedanmark, Ringsted-Fehmarn The railway connecting Europe, project introduction book, pp. 6.

[12] Madsen, S. N., Personally interviewed on 22 November 2012, Head of department, Rail, Ramboll, Fredericia, Denmark.

[13] Niras, Syd_P095 Sporspcerringsmønstres indflydelse på anlogsprisen, pp. 1-7, 2011 (Danish).

[14] Li, R., Landex, A. \& Nielsen, O. A., The potential cost from passengers and how it impacts railway maintenance and renewal decisions, the annual transport conference at Aalborg University 2013, pp. 4-9, 2013. 